\title{
Scratch Testing of Hard Ceramics: Manifestation of Viscoelasticity
}

\author{
Witold Brostow $^{1,2}$, Nathalie Hnatchuk ${ }^{1} \&$ Janusz Prazuch ${ }^{2}$ \\ ${ }^{1}$ Laboratory of Advanced Polymers \& Optimized Materials (LAPOM), Department of Materials Science and \\ Engineering and Department of Physics, University of North Texas, USA \\ ${ }^{2}$ College of Mechanics and Robotics, AGH University of Science and Technology, Adama Mickiewicza, Poland \\ Correspondence: Witold Brostow, Laboratory of Advanced Polymers \& Optimized Materials (LAPOM), \\ Department of Materials Science and Engineering and Department of Physics, University of North Texas, 3940 \\ North Elm Street, Denton TX 76207, USA. E-mail: wkbrostow@gmail.com
}

Received: May 5, 2019

doi:10.5539/jmsr.v8n3p18
Accepted: July 15, 2019

Online Published: July 24, 2019

URL: https://doi.org/10.5539/jmsr.v8n3p18

\begin{abstract}
Viscoelasticity is studied extensively in polymers and polymer-based composites-but hardly in ceramics. We have studied viscoelastic behavior of three ceramics as manifested in scratching tests: 98 weight $\% \mathrm{~B}_{4} \mathrm{C}+2 \%$ hexagonal boron nitride (h-BN), $92 \% \mathrm{~B}_{4} \mathrm{C}$ and $8 \% \mathrm{~h}-\mathrm{BN}, 91 \% \mathrm{~B}_{4} \mathrm{C}+5 \% \mathrm{CrSi}_{2}+2 \% \mathrm{~h}-\mathrm{BN}$. Clear viscoelastic recovery (the groove depth becoming shallower within 2 minutes) is seen in all three materials, the recovery in each case of at least $90 \%$. Taking into account viscoelasticity and introducing appropriate additives, one could significantly improve the scratch resistance of the boron carbides, and possibly of other hard ceramics as well.
\end{abstract}

Keywords: Ceramics Viscoelasticity, Ceramics Scratch Resistance, Boron Carbides

\section{Introduction and Scope}

Ceramic materials have a fairly large variety of applications. Thus, silver tantalite films can be used as lubricious materials for moving assemblies at temperatures as high as $750^{\circ} \mathrm{C}$ (Stone et al., 2013). Kleinlogel and Gauckler (2001) have created very high density $\mathrm{CeO}_{2}$-allowing tailoring its electrical properties for numerous electrochemical applications. Nanocrystalline $\mathrm{ZnO}$ can provide low friction (Mohseni et al., 2012). Ceramic hydroxyapatite developed by Ueshima et al. (2002) can store large electric charges. Carbajal de la Torre et al. (2009) developed silica based ceramic coatings for corrosion protection of steels. Chen and Du (2014) studied a lithium lanthanum titanate as a promising solid electrolite-not experimentally but by molecular dynamics and atomistic computer simulations. Salonen and Mäkilä (2018) note applications of porous silicon in areas as diverse as luminescence, drug delivery and battery technology. Braun et al. (2018) have developed a method of fabrication of entropy-stabilized ceramics with low thermal conductivity while mechanically strong at the same time. A group at the Royal Institute of Technology in Stockholm (Larsson et al., 2000) reported scratch and indentation testing of TiN coatings on steel structures. Related to this is the development by Gonczy and Randall (2005) of an ASTM standard for Adhesion Strength and Mechanical Failure Modes of Ceramic Coatings by Quantitative Scratch Testing. Rapidly growing is application of ceramic components in human bodies in replacements of bones (St. John, 2015; Morrison et al., 2015; McEntire, 2016). One could provide still more examples, largely leading to the following conclusion: ceramic materials are being developed mostly aiming at their specific electrical, mechanical, and/or thermophysical properties.

Relatively less work is devoted to tribology of hard ceramics-their behavior during scratch testing in particular. Interestingly, Singh and Shawla (2012) studied $\mathrm{Al} / \mathrm{SiC}$ nanolaminates at a constant loading rate. They observed that layers of $\mathrm{Al}$ and $\mathrm{SiC}$ (each 50-60nm thick), can exhibit better scratch resistance and recovery than monolithic thin films of $\mathrm{Al}$ or $\mathrm{SiC}$.

Viscoelastic behavior means that the material shows simultaneously partly elastic (solid-like) and partly flowing liquid behavior (Lucas et al., 2001; Gedde, 2001; Brostow \& Hagg Lobland, 2017). In such a material there is change of properties with time. The phenomenon manifests itself easily in polymers and polymer-based materials-and has also been seen in copper pastes (Brostow et al., 2010). When viscoelasticity manifests itself in scratch testing, the bottom of the groove created by the indenter goes up to a varying extent. The process takes place inside of 2 minutes; after 2 minutes at least 99\% recovery has taken place. That recovery, so well known in polymers, has been hardly studied in ceramics. 
In this situation, we decided to focus on viscoelastic recovery in scratch resistance testing for a small number of hard ceramics. As discussed by Balakrishnan et al. (2007), boron carbide is a well-known ceramic possessing very high hardness (at least $30 \mathrm{GPa}$ ), low density $\left(2.5 \mathrm{~g} / \mathrm{cm}^{3}\right)$, stable thermal properties (the melting temperature $\approx$ $2500^{\circ} \mathrm{C}$ ) and also a relatively low price. Such properties make boron carbide a material used for wear resilient coatings, body armors and abrasive grids (Yang et al., 2018). However, these various applications of boron carbides are impeded due to abnormally easy shear-induced brittle fracture. Thus, utilizing concept of viscoelasticity by introducing property modifying additives, one could significantly improve the scratch resistance of the boron carbides, and possibly of other hard ceramics as well. In this situation, we have studied scratch resistance of three ceramics based on boron carbide.

\section{Materials and Methods}

Boron carbide $\left(\mathrm{B}_{4} \mathrm{C}\right)$, hexagonal boron nitride $(\mathrm{h}-\mathrm{BN})$ and chromium disilicide $\left(\mathrm{CrSi}_{2}\right)$ were obtained from H.C. Starck, Coldwater, Michigan. A composition called below b2h consisted of 98 weight $\% \mathrm{~B}_{4} \mathrm{C}+2 \%$ hexagonal boron nitride (h-BN). The second series of samples called b8h consisted of $92 \% \mathrm{~B}_{4} \mathrm{C}$ and $8 \% \mathrm{~h}-\mathrm{BN}$. The third series of samples called bcs $2 \mathrm{~h}$ contained $5 \% \mathrm{CrSi}_{2}, 2 \% \mathrm{~h}-\mathrm{BN}$, the reminder being $\mathrm{B}_{4} \mathrm{C}$. The minority components are uniformly distributed in boron carbide by the H. C. Starck manufacturer.

The scratch testing was performed on a machine from CSM instruments/Anton Paar (Serial No. I-125, upgraded). Each specimen was subjected to linear scratching along the distance of $5.0 \mathrm{~mm}$ at the rate of $5.33 \mathrm{~mm} / \mathrm{min}$. We have used a diamond tip indenter with the tip radius of $100 \mu \mathrm{m}$. The depth resolution claimed by the industry is $0.3 \mathrm{~nm}$. The scratch tester allows three modes of operation: a constant load, a linearly increasing load, and also a stepwise increasing load. In our procedure, in the first step the sample surface was pre-scanned at a low scanning load of $0.03 \mathrm{~N}$. This because no material surface is really flat-and this statement applies to both synthetic materials and for instance also to human teeth (Brostow \& Hagg Lobland, 2017). Then, the scratch test was performed over the scanned profile with linearly increasing load starting from $0.03 \mathrm{~N}$ to $25.00 \mathrm{~N}$. Changes in the depth profile and acoustic emissions were recorded during the progress of the indenter. Once the scratch was made, we allowed the sample to undergo two minutes of recovery followed by a recovery scan at the scanning load of $0.03 \mathrm{~N}$. An integrated microscope allowed optical imaging.

\section{Results and Discussion}

Scratch testing results so obtained for a b2h sample are displayed in Figure 1. Other samples of the same composition had very similar results.

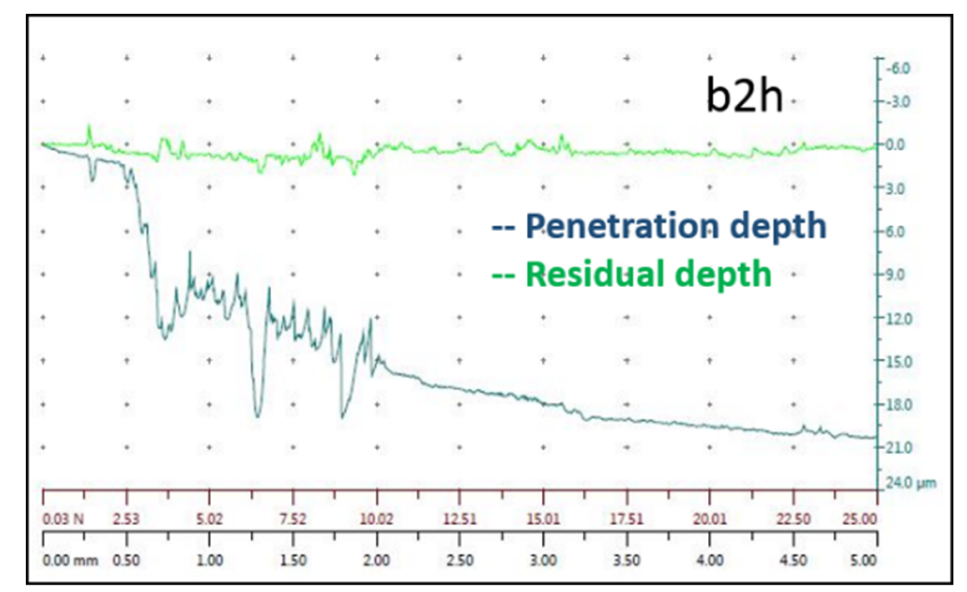

Figure 1. Penetration and recovery depth as a function of the linearly increasing load for the $\mathrm{b} 2 \mathrm{~h}$ sample

As said, the scratching covered the distance of $5 \mathrm{~mm}$ and up to the $25 \mathrm{~N}$ load. As expected, the surface is anything but smooth. A virtually full recovery is seen-something unheard of for polymers. This while at the $25 \mathrm{~N}$ load the penetration depth is $20.3 \mu \mathrm{m}$. The behavior of the predominantly $\mathrm{B}_{4} \mathrm{C}$ sample can be related to known mechanical behavior of ceramics in tensile testing (Brostow \& Hagg Lobland, 2017): the linear elastic region is followed almost immediately by the fracture. We have not observed any crack formation, crack propagation or fracture. Thus, the deformation caused by the diamond indenter falls within the elastic region.

Scratch testing results for a b8h sample are displayed in Figure 2. 


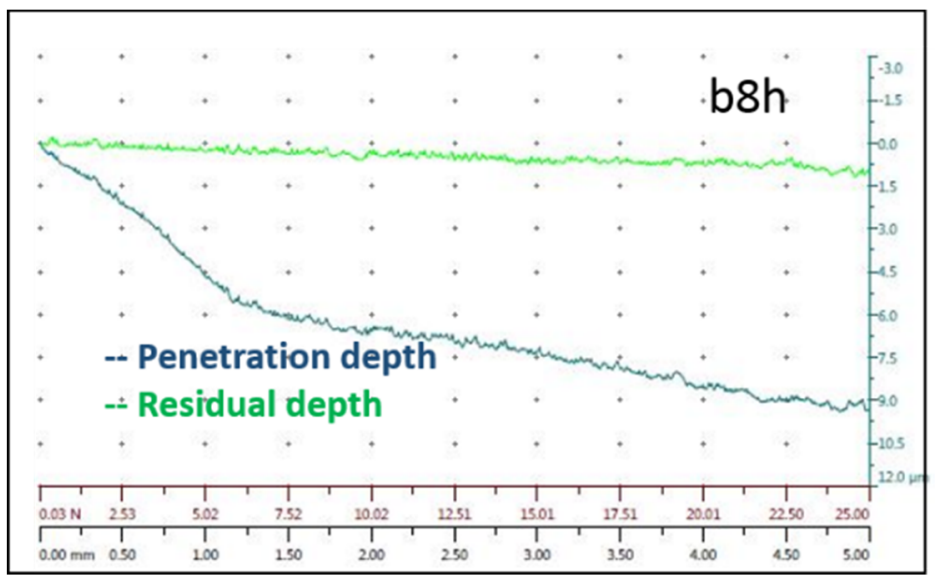

Figure 2. Penetration and recovery depth as a function of the linearly increasing load for a b8h sample

We now compare the results presented in the first two Figures. The maximum penetration depth decreased from $20.3 \mu \mathrm{m}$ to $9.3 \mu \mathrm{m}$, as the concentration of boron carbide was increased from $2 \%$ to $8 \%$. However, the h-BN addition resulted in slight decrease in recovery depth of the sample. At $25 \mathrm{~N}$ we see that the residual or healing depth $R_{h}$ is close to $1.0 \mu \mathrm{m}$ for the $\mathrm{b} 8 \mathrm{~h}$ sample. This result could be related to a slight amount of plasticity introduced by the addition of h-BN. It is known that h-BN is the softest among BN polymorphs (and the most stable). It is for this reason that $\mathrm{h}-\mathrm{BN}$ is used as a lubricant and an additive to cosmetic products.

Finally, in Figure 3 we present results for a bcs $2 \mathrm{~h}$ sample.

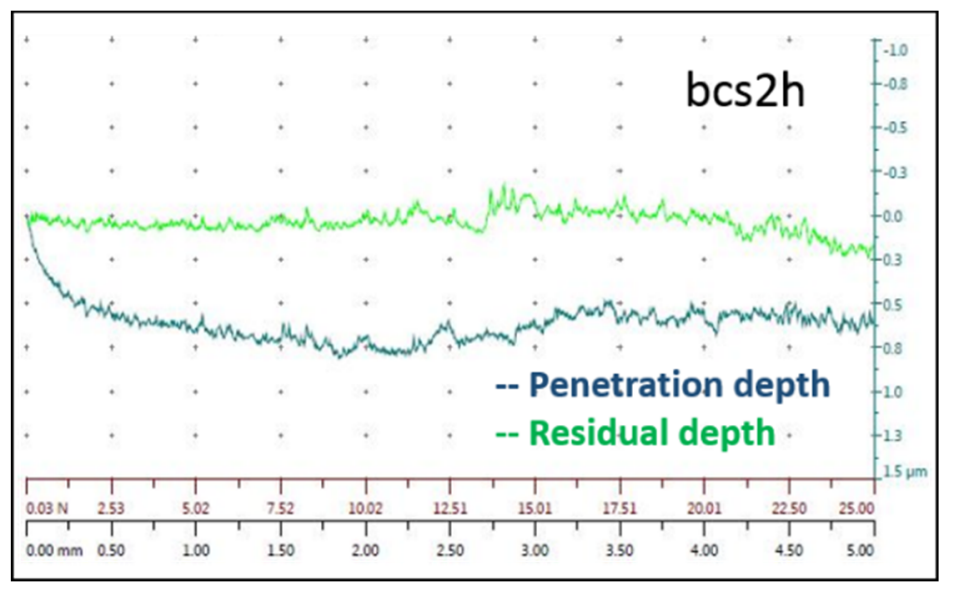

Figure 3. Penetration and recovery depth as a function of the linearly increasing load for a bcs $2 \mathrm{~h}$ sample

We recall that each bcs $2 \mathrm{~h}$ sample contains $93 \% \mathrm{~B}_{4} \mathrm{C}, 5 \% \mathrm{CrSi}_{2}$ and $2 \% \mathrm{~h}-\mathrm{BN}$. Compared with b8h samples, we have $1 \%$ less $\mathrm{B}_{4} \mathrm{C}$-not a significant change; we have the same concentration of $\mathrm{BN}$, hence the important change is the presence of $\mathrm{CrSi}_{2}$. We see a fairly dramatic decrease in the penetration depth $\mathrm{R}_{\mathrm{p}}$ as compared to $\mathrm{b} 8 \mathrm{~h}$. Apparently $5 \%$ of $\mathrm{CrSi}_{2}$ imparts enhanced immunity, even against temporary effects of diamond scratching. One can even say that the immunity is of two kinds. First, the values of $R_{p}$ are lower than for the other two hard ceramics studied. Second, at $2 \mathrm{~mm}$ of scratching the load stands at $10 \mathrm{~N}$. At higher values of the load the penetration depth $R_{p}$ does not increase anymore. At $25 \mathrm{~N}$ the healing depth $R_{h}$ is below $0.3 \mu \mathrm{m}$, the lowest for the three samples.

In Figure 4 we show images of the three samples, one of each kind, after scratch testing.

Observation of the images agrees with the scratching results reported above. The trace of the indenter passage for the bcs $2 \mathrm{~h}$ sample (Figure 4c) is the 'weakest' or the least pronounced among the three-as reflected in the curves displayed in Figures 1-3. 


\section{Scratch distance $=5 \mathrm{~mm}$}

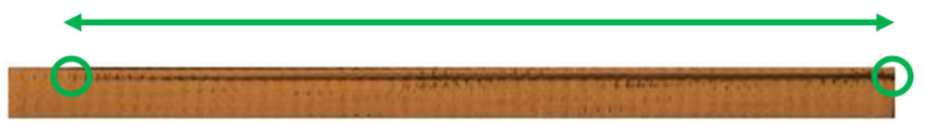

(a) b2h

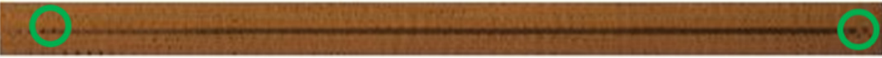

(b) $\mathrm{b8h}$

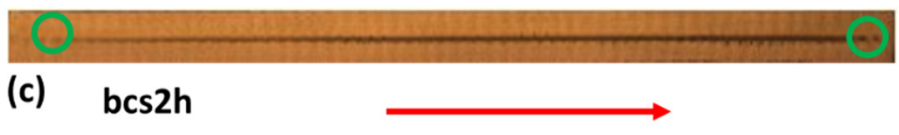

Direction of scratch

Figure 4. Images of the samples after scratch testing

\section{Concluding Remarks}

Considering our results against literature reports on ceramics, we reinforce the impression noted above: investigation of ceramics is related largely to their applications. Thus, $\mathrm{WO}_{3}$-based composites can be used in photochromic smart windows (Miyazaki, Ishigaki, \& Ota, 2017). Electric generation characteristics of piezoelectric ceramics was studied under cyclic bending loading (Yang et al., 2019). Varistors in which electrical resistance varies with the applied load are also being studied (Miyazaki et al., 2018). The situation with metals is different, their tribological properties are studied, such as the surface roughness of steels (Abbas, 2016). We find that tribological properties of ceramics deserve more attention-even from the point of view of applications.

Since the seminal work of Myshkin and coworkers (2005) tribology of polymers is relatively well understood while clearly more work is needed on interactions involving rough surfaces. We also note a result from earlier work on low density polyethylene: lowering roughness results in higher microhardness, lower wear rates and higher scratch resistance (Janczewski et al., 2016). Such issues also deserve future work for ceramics.

To provide a broad perspective on our results, we note that scratch testing is the oldest method of tribological characterization of materials. This because scratching is the basis of the hardness scale of materials developed in 1812 by Friedrich Mohs. A remarkable achievement at that time - particularly if one takes into account the fact that the word 'tribology' was created only in 1966 (Jost). A committee of the British Government charged with defining the main line of progress for the industry of the United Kingdom concluded in 1966 that tribology is that line - and also coined a word describing that area of activity.

\section{Acknowledgements}

A lecture by Roald Hoffmann entitled "Some interesting things about carbides" at the Polychar World Forum on Advanced Materials held in Singapore provided an inspiration for this work.

\section{Conflict of interests}

The authors declare that there is no conflict of interests regarding the publication of this paper.

\section{References}

Abbas, A. T. H. (2016). Influence of Process Parameters on the Surface Roughness during turning operation of High Strength Steel. J. Mater. Sci. Res., 5(2), 100-110.

Balakrishnarajan, M. M., Panchatna, P. D., \& Hoffmann, R. (2007). Structure and bonding in boron carbide: The invincibility of imperfections. New J. Chem., 31, 473.

Braun, J. L., Rost, C. M., Lim, M., Giri, A., ..., \& Hopkins, P. E. (2018). Charge-Induced Disorder Controls the Thermal Conductivity of Entropy-Stabilized Oxides. Adv. Mater., 30, 1805004.

Brostow, W., \& Hagg Lobland, H. E. (2017). Materials: Introduction and Applications. John Wiley \& Sons.

Brostow, W., Datashvili, T., McCarty, R., \& White, J. B. (2010). Copper viscoelasticity manifested in scratch recovery. Mater. Chem. Phys., 124, 371-376. 
Carbajal-de la Torre, G. M., Espinoza-Medina, M. A., Martinez-Villafañe, A., Gonzalez-Rodriguez, J. G., \& Castaño, V. M. (2009). Study of ceramic and hybrid coatings produced by the sol-gel method for corrosion protection. Open. Corr. J., 2, 197-203.

Chen, Ch., \& Du, J. (2014). Lithium Ion Diffusion Mechanism in Lithium Lanthanum Titanate Solid-State Electrolytes from Atomistic Simulations. J. Am. Ceram. Soc., 98, 534-542.

Gedde, U. W. (2001). Polymer Physics. Kluver, Dordrecht-Boston-London.

Gonczy, S. T., \& Randall, N. (2005). An ASTM standard for quantitative scratch adhesion testing of thin, hard ceramic coatings. Int. J. Appl. Ceram. Tech., 2, 422-428.

Janczewski, L., Tobola, D., Brostow, W., Czechowski, K., Hagg Lobland, H. E., Kot, M., \& Zagorski, K. (2016). Effects of ball burnishing on surface properties of low density polyethylene. Trib. Int., 93, 36-42.

Jost, H. P. (1996). Tribology Education and Research: Report on the Present Position and Industry's Needs. HM Stationary Office, London.

Kleinlogel, C., \& Gaucker, L. J. (2001). Sintering of nanocrystalline $\mathrm{CeO}_{2}$ ceramics. Adv. Mater., 13, 1081-1085.

Larsson, M., Olsson, M., Hedenqvist, P., Hogmark, S., \& Bergmann, E. (2000). Mechanisms of coating failure as demonstrated by scratch and indentation testing of TiN coated HSS. Surf. Eng., 16, 436.

Lucas, E. F., Soares, B. G., \& Monteiro, E. (2001). Caracterização de Polimeros. e-Papers, Rio de Janeiro.

McEntire, B. J., Lakshminarayanan, R., Ray, D. A., Clarke, I. C., Puppulin, L., \& Pezzotti, G. (2016). Silicon nitride bearings for total joint arthroplasty. Lubricants, 4, 35 .

Miyazaki, H., Ishigaki, T., \& Okayasu, M. (2018). Effect of $\mathrm{Na}_{2} \mathrm{O}$ and $\mathrm{B}_{2} \mathrm{O}_{3}$ Addition on Nonlinear Electrical Properties of $\mathrm{WO}_{3}$-Based Capacitor-Varistors. J. Mater. Sci. Res., 7(4), 53-58.

Miyazaki, H., Ishigaki, T., \& Ota, T. (2017). Photochromic Smart Windows Employing $\mathrm{WO}_{3}$-Based Composite Films. J. Mater. Sci. Res., 6(4), 62-66.

Mohs, F. (1812). Versuch einer Elementar-Methode zur naturhistorischen Bestimmung und Erkennung der Foßilien, Wien.

Mohseni, H., Mensah, B. A., Gupta, N., Srinivasan, S. G., \& Scharf, T. W. (2012). On tailoring the nanocrystalline structure of $\mathrm{ZnO}$ to achieve low friction. Tribol. Lubr. Tech., 17-19.

Morrison, M. L., Jani, S., \& Parikh, A. (2015). Design of advanced bearing system for total knee arthroplasty. Lubricants, 3, 475-492.

Myshkin, N. K., Petrokovets, M. I., \& Kovalev, A. V. (005). Tribology of polymers: Friction, wear and mass transfer. Tribol. Int., 38, 910-21.

Salonen, J., \& Mäkilä, E. (2018). Thermally carbonized porous silicon and its recent applications. Adv. Mater., 30, 1703819.

Singh, D. R. P., \& Chawla, N. (2012). Scratch resistance of Al/SiC/ metal ceramic laminates. J. Mater. Res., 27, 278-283.

St. John, K. R. (2015). Evaluation of two total heap bearing materials for resistance to wear using a hip simulator. Lubricants, 3, 459-474.

Stone, D. S., Harbin, S., Mohseni, H., Mogonye, J. E., ..., \& Aouadi, S. M. (2013). Lubricious silver tantalate films for extreme temperature applications. Surf. Coat. Tech., 217, 140-146.

Ueshima, M., Nakamura, S., \& Yamashita, K. (2002). Huge, Millicoulomb Charge Storage in Ceramic Hydroxyapatite by Bimodal Electric Polarization. Adv. Mater., 14, 591-595.

Yang, L., Nagano, H., \& Okayasu, M. (2019). Experimentally and Numerically Analyzed Piezoelectric Characteristics of PZT Ceramics. J. Mater. Sci. Res., 8(1), 10-16.

Yang, X., Coleman, S. P., Lasalvia, J. C., Goddard, W. A., \& An, Q. (2018). Shear-Induced Brittle Failure along Grain Boundaries in Boron Carbide. ACS Appl. Mater. Interfaces, 20, 5072.

\section{Copyrights}

Copyright for this article is retained by the author(s), with first publication rights granted to the journal.

This is an open-access article distributed under the terms and conditions of the Creative Commons Attribution license (http://creativecommons.org/licenses/by/4.0/). 